\title{
CHLORPROMAZINE (LARGACTIL) AS A PREMEDICATION IN OPHTHALMIC SURGERY*
}

\author{
BY \\ J. GIBSON MOORE \\ London
}

AN attempt has been made to assess the value of chlorpromazine (Largactil) as a premedication before operation. This drug has been described as having a marked cerebral depressant action (Delay and Deniker, 1953), and a definite action in calming psychomotor activity (Winkelman, 1954), being anti-emetic (Friend and Cummins, 1953), enhancing the value of other analgesic drugs, and reducing pain (Sadove and others, 1954). All of these reputed properties would be helpful in ophthalmic surgery and any drug which could produce a state of emotional disinterestedness without apparent loss of intellect must command our attention.

Anaesthetists have been extremely interested in the use of chlorpromazine often in conjunction with promethazine in the production of hypothermia, and claims have been made that danger is greatly reduced in " poor-risk" cases through the absence of post-operative shock (Smith and Fairer, 1953). Operative shock is not a factor requiring special consideration in ophthalmic surgery, but the patients' nervousness may be allayed by the oral use of this drug before operation, and the operation itself may be performed under local anaesthesia.

\section{Material}

A series of 58 patients received chlorpromazine as a premedication before surgery (see Table); 36 others acted as "controls". Out of a total of 94, 68 operations were for cataract, ten for glaucoma, four for retinal detachment, and the remainder for miscellaneous conditions such as dacryocystorhinostomy.

The period of hospitalization before operation was 4 days; a longer stay than this was often inconvenient and a shorter stay would not allow sufficient time for the drug to act. Each patient was asked whether they had been using any type of sedative at home which might confuse the results and if so this was discontinued.

Three patients were operated upon under general anaesthesia, after use of the drug (see p. 111).

In an investigation of this type one is straight away confronted with the difficulty of lack of rigid controls, and much reliance has to be placed on clinical judgement which is notoriously unreliable. The only available method is to make the patients themselves become their own controls. Before admission I prescribed alternative premedication and the house surgeon or sister chose one or the other at random, so that I did not know until the end of the operation whether or not the patient had been given chlorpromazine.

*Received for publication November 29, 1954 


\section{Dosage}

When chlorpromazine was given the following dosage schedule was adhered to irrespective of body weight.

1st day - - - - - $\quad 50 \mathrm{mg}$. twice daily by mouth.

2nd, 3rd, and 4th day _ - $\quad 50 \mathrm{mg}$. three times daily by mouth.

45 minutes before the operation 2 gr. sod. amytal.

More than 4 days' premedication was not practicable, and the long period of 7 or 8 weeks described by Elkes and Elkes (1954) was clearly impossible.

\section{Results}

The patients' behaviour at operation was divided into three groups: excellent, good, and unco-operative (Table). It was easy to place cases in the third group, but it will be appreciated that it was often difficult to distinguish between "excellent" and "good". Nevertheless, an attempt was made to classify each patient as accurately as possible. With regard to the preoperative course, it became clear that chlorpromazine has an unpredictable effect when given by mouth alone. In many cases it had a marked effect in reducing anxiety and tension, and in these the operation proceeded so smoothly that the patient's " reactions" were non-existent, but in others it was difficult to judge whether the drug was having any effect at all.

TABLE

RESULTS OBTAINED

\begin{tabular}{|c|c|c|c|c|c|}
\hline \multirow{2}{*}{\multicolumn{2}{|c|}{ Drug Used }} & \multicolumn{4}{|c|}{ Patients' Behaviour } \\
\hline & & \multirow{2}{*}{$\frac{\text { Excellent }}{35}$} & \multirow{2}{*}{$\frac{\text { Good }}{23}$} & \multirow{2}{*}{$\frac{\text { Unco-operative }}{\text { Nil }}$} & \multirow{2}{*}{$\frac{\text { Total }}{58}$} \\
\hline Chlo & No. & & & & \\
\hline Cinotpionilazuite & Per cent. & 60 & 40 & - & 100 \\
\hline \multirow{2}{*}{ Barbiturate } & No. & 18 & 15 & 3 & 36 \\
\hline & Per cent. & 50 & 41 & 9 & 100 \\
\hline
\end{tabular}

The analysis shows that the only three rather unco-operative patients had received a barbiturate (phenobarbitone) alone. The percentage of excellent cases was greater (60 per cent.) among the patients given chlorpromazine than in the rest ( 50 per cent.) and the "good" cases show approximately the same proportion.

Questioning the patients afterwards proved to be of little value. Most patients are so grateful after operation that their answers are biased, and after discharge from hospital their memory for detail is often lost. Three patients volunteered the information that the drug given produced a "don't care " feeling and removed all fear of the operation, but most of the others merely became drowsy and their response could only be judged by their quiet behaviour on the table. 
Reverting to clinical impressions alone, I thought that chlorpromazine given in the doses mentioned did produce a calmer, more co-operative patient. It seems to me that barbiturates given alone may make a patient drowsy even to the point of sleeping, but do not diminish the fear of and reaction to the pain produced by the necessary injections, nor do they allay pre-operative anxiety. Chlorpromazine seems to produce a more relaxed patient, and an uneventful post-operative period.

Complications.-Various complications have been described, such as tachycardia, jaundice, polyuria, dryness of the mouth, and gastro-intestinal upsets, but with the doses given none of these was encountered in the present series. In the cases in which a profound effect was produced by the drug a certain degree of pallor of the skin was noticeable, and this will give a clinical indication of whether or not the drug is effective.

\section{General Anaesthesia}

The results obtained in three cases under general anaesthesia were uniform. Numerous reports in the journals of other specialties assess the value of the drug in other types of operation.

Case Report.-A typical result (a case of retinal detachment) is recorded below. General anaesthesia was selected in this case because the patient was of low intelligence, uneducated, and grossly apprehensive.

9.30 a.m. Premedication: Chlorpromazine $50 \mathrm{mg}$. orally; atropine $1 / 100 \mathrm{~g}$. intramuscularly.

9.55 a.m. Intravenous injection of pethidine $150 \mathrm{mg}$. and Largactil $100 \mathrm{mg}$. in two divided doses over a period of 20 minutes.

10.15 a.m. Patient asleep but able to respond to questions in a drowsy fashion.

$10.30 \mathrm{a} . \mathrm{m}$. Insertion of nasopharyngeal airway lubricated with xylocaine ointment. Only

10.30 a.m. Operation commenced.

11.10 a.m. Operation ended.

12.30 p.m. Airway removed. No coughing.

2.00 p.m. Patient conscious. No vomiting. No nausea. No pain.

If all cases reacted in this manner the method would bə ideal and the chief post-operative drawback of general anaesthesia, i.e. vomiting and coughing, would be avoided. If surgery is preferred under general anaesthesia this method deserves consideration provided skilled anaethetists are available.

\section{Conclusion}

Chlorpromazine (Largactil) is a satisfactory premedication before ocular surgery. It appears to have many advantages over the more commonly used barbiturates alone. However, while in some cases a state of complete emotional neutrality is produced, in others the drug has no noticeable effect. In no case has an adverse effect been observed when the drug has been used either orally or generally.

\section{REFERENCES}

Delay, J., and Deniker, P. (1953). Thérapie, 8, 347.

ElKeS, J., and ElKES, C. (1954). Brit. med. J., 2, 560.

Friend, D. G., and Cummins, J. F. (1953). J. Amer. med. Ass., 153, 480.

Sadove, M. S., Levin, M. J., Rose, R. F., Schwartz, L., and WitT, F. W. (1954). Ibid., $155,627$.

SMITH, A., and FAIRER, J. G. (1953). Brit. med. J., $2,1247$.

Winkelman, N. W. (1954). J. Amer. med. Ass., 155, 18. 